\title{
El discurso político en los cuerpos complejos de la monarquía castellana (s. XIII-XVIII) Narrativas de poder, comunicación y negociación $^{1}$
}

\author{
The political discourse in the complex bodies of the Castilian monarchy (s. XIII- \\ XVIII) Narratives of power, communication and negotiation
}

\section{María Inés Carzolio \\ micarzolio@fibertel.com.ar \\ Universidad Nacional de La Plata, Argentina}

\author{
Víctor Muñoz Gómez \\ vmunozgo@ull.edu.es \\ Instituto de Estudios Medievales y Renacentistas, \\ Universidad de La Laguna, España
}

Recepción: 05 Agosto 2020

Aprobación: 18 Septiembre 2020

Publicación: 04 Enero 2021

Cita sugerida: Carzolio, M. I. y Muñoz Gómez, V. (2021)

El discurso político en los cuerpos complejos de la monarquía castellana (s. XIII-XVIII) Narrativas de poder, comunicación y negociación. Trabajos y Comunicaciones, (53), e136. https://doi.org/10.24215/23468971e136
Resumen: La presente selección de artículos tiene por objetivo cerrar el monográfico iniciado en el número anterior de la revista acerca de la complejidad que exhiben los discursos políticos en la sociedad europea -y más particularmente en el caso de la sociedad política castellana- de la Baja Edad Media y la Temprana Modernidad. Inscritos al interior de una visión corporativa, profundamente jerarquizada y orgánica, estos sistemas estructurados de definición, identificación y comunicación que otorgan sentido organizan y legitiman el conjunto agregativo del entramado de actores que definen los distintos cuerpos y corporaciones. $\mathrm{Su}$ análisis nos permite componer los distintos marcadores sociales que los constituyen y le otorgan inteligibilidad. Los trabajos aquí presentados dialogan con aquellos publicados en la primera parte del monográfico, atendiendo a actores como la monarquía, las elites aristocráticas y urbanas o los sectores populares rururbanos y escenarios de interacción político-social como la corte, las Cortes o las instituciones concejiles.

Palabras clave: Discurso Político, Cuerpos, Monarquía, Actores, Análisis Situacional.

Abstract: The present selection of articles aims to conclude the monographic dossier bout the complexity exhibited by political discourses in European society -most specifically in the case of Castilian political society- during Late Middle Ages and Early Modern Ages. Registered within a corporate vision, deeply hierarchical and organic, these structured systems of definition, identification, and communication that give meaning organize and legitimize the aggregate set of the network of actors that define the different bodies and corporations. Its analysis allows us to compose the different social markers that constitute it and grant it intelligibility. The papers that we are pleased to present here are undertaken in dialogue with those included in the first part of the dossier, dealing with players such as the monarchy, aristocratic and urban elites or urban and urban-rural commoners as well as with different settings for socio-political interaction such as the Court, the 'Cortes' - deliberative assemblies of the kingdom- or the communal self-government institutions.

Keywords: Political Discourse, Bodies, Monarchy, Actors, Situational Analysis. 
Tenemos el placer de presentar aquí la segunda parte del dossier monográfico iniciado en el número anterior de esta revista acerca de los discursos políticos en los cuerpos complejos de la monarquía castellana entre el final de la Edad Media y los inicios de la Temprana Modernidad. ${ }^{2}$ Como no podía ser de otro modo, los trabajos que la componen se armonizan en diálogo con aquellos publicados en la primera parte del monográfico. De este modo, el objetivo de este segundo bloque del dossier es insistir en las reflexiones que Osvaldo Víctor Pereyra e Israel Sanmartín Barros proponían en su presentación del primer bloque. Esto es, por una parte, discurrir en el estudio de distintas manifestaciones de discursos que entendemos como «políticos» en la sociedad castellana tardomedieval y altomoderna alrededor de nociones como las de «núcleos de sentido» (del discurso), «gramáticas de poder»y «gramáticas de la acción discursiva». Por otra parte, ser capaces de analizar los diferentes niveles de discurso manejados por agentes socio-políticos diversos con el fin de penetrar en la definición e identificación de marcadores sociales y de identidad colectiva de dichos «cuerpos complejos» y en la propia comprensión de las dinámicas de acción, enfrentamiento y negociación entre dichos agentes presentes en la sociedad política castellana. Al fin, reflexionar acerca de la posible conformación de las bases una «cultura política» común en la Castilla bajomedieval y de su influencia y evolución en el conjunto del ámbito hispánico y occidental -el cual terminaría englobando, como es bien sabido, también el hemisferio americano- entre los siglos XIII-XVIII (Pereyra, O. y Sanmartín Barros, I.; 2020).

En este sentido, con el fin de no abundar sobre lo ya expuesto por Pereyra y Sanmartín, remitimos a los lectores a sus palabras introductorias y a las referencias conceptuales y metodológicas puestas sobre la mesa por ellos. Partiendo, pues, de perspectivas propias de la historia social del poder y de la apertura a abordajes metodológicos diversos, en efecto, venimos a preguntarnos sobre los mismos procesos de construcción de la monarquía como proyecto político y como organización compleja para el ejercicio del poder y la redistribución de sus beneficios. Una construcción a lo largo del tiempo, al fin, resultado de la competencia, el enfrentamiento y la armonización entre múltiples instancias de poder y agentes sociales activos en ellas. Este debate tiene ya un largo recorrido desde las reflexiones acerca de la naturaleza del poder político y la existencia del Estado al final de la Edad Media y durante todo el Antiguo Régimen (Clavero, B., 1986, Hespanha, A. M., 1989, Fernández Albaladejo, P., 1992) pero, por lo que respecta a la Corona de Castilla entre el final del siglo XIII y el inicio del siglo XVI, ha dado lugar a más que interesantes reflexiones alrededor de la conformación del estado autoritario monárquicos y de sus aparatos políticos, administrativos, hacendísticos o militares (Genet, J. P., 1990, 2003; Strayer, J., 2005; para el ámbito hispánico y castellano, Maravall, J. A., 1972; Rucquoi, A., 1987; Monsalvo Antón, J. Ma , 1986, 2019) y a la propia interconexión entre agencias de poder en dicho proceso, muy particularmente la propia monarquía, las aristocracias señoriales, las comunidades urbanas, sin olvidar tampoco a la Iglesia (Nieto Soria, J. M., 1999, 2006; Monsalvo Antón, J. Ma , 2017, 2019).

Estos actores -la monarquía y sus titulares, las elites aristocráticas y urbanas o los sectores populares de ciudades y sus entornos rurales- y distintos escenarios de su interacción político-social como la corte, las Cortes o las instituciones concejiles son abordados en esta segunda parte de nuestro dossier monográfico a partir del propósito común de atender mejor los niveles de interconexión y comunicación establecidos entre ellos en ese proceso de conformación de lo que se ha venido a llamar «Estado moderno» (Martín Cea, J. C. y Oliva Herrer, H. R., 2012; Hattori, Y., 2014; Nieto Soria, J. M. y Villarroel González, O., 2018). Así, la atención a la elaboración y despliegue de discursos específicos, adecuados a espacios, contextos representativos y lenguajes comunicativos diferentes, por parte de esos agentes integrantes de la sociedad política de la Corona 
de Castilla nos ayuda a comprender mejor la concurrencia de distintos constructos intelectuales en torno al ejercicio del poder y su operatividad a la hora de imponer o negociar determinadas visiones de la realidad acerca del orden y la jerarquía en tal sociedad y en torno a dicho ejercicio del poder. (Menache, S., 1990; Chartier, R., 1992, Dumolyn, J., 2012; Howarth, D., Norval A. J. y Stavrakakis Y., 2000; Dijk, T., 2009; Jara Fuente, J. A., 2011, 2017a, 2017b; Monsalvo Antón, J. Ma: 2019). El resultado de tal balance de estrategias discursivas y de su capacidad performativa, entendido de la mano del propio choque y equilibrio de fuerzas entre agentes e instancias en cuanto a la acción política y social en la comunidad del reino, nos aproxima a ese horizonte de conformación corporativa de la monarquía castellana entre el Medievo y la Temprana Modernidad y, por su puesto, a la cristalización de discursos predominantes en torno a tal comunidad política, aceptados y compartidos de forma mayoritaria dentro la sociedad feudal de la Castilla entre los siglos XIIIXVI.

La lectura de los seis artículos que componen esta parte del dossier nos coloca ante acercamientos a temáticas muy diversas: la inserción de la exégesis milenarista en el contexto castellano del siglo XV (Sanmartín Barros), los debates en torno a la riqueza del rey y de su empleo lícito y la legitimidad de ciertas exigencias de exacción fiscal por parte de la Corona a mediados de esta centuria (Ortego Rico), las interpretaciones críticas del cortesano y del escenario político de la Corte en la tratadística al respecto de los siglos XVI-XVII (Carzolio), la identidad en torno a la posición de poder de la pequeña aristocracia hidalga del área cantábrica (Pereyra), la consideración acerca de la diferente caracterización de ciertas actitudes de grupos de elite y sectores populares urbanos en la cronística regia ibérica (Díaz Marcilla), el reconocimiento de trazas de un discurso propio de identidad y acción política local de los sectores populares de las ciudades castellanas (Mondragón). Las posibilidades de ordenación de estos trabajos eran múltiples. Sin embargo, hemos entendido apropiado que, atendiendo a los criterios que se señalará a continuación, era posible armonizarlos más allá del simple correlato cronológico. Dichos criterios fueron, de una parte, las características de las fuentes estudiadas. De la otra, los agentes productores de las mismas, referidos en ellas o, incluso, destinatarios del discurso inscrito en los textos. Igualmente, los espacios de interacción sociopolítica o de referencia de la acción discursiva a los que remiten las fuentes.

Así, nos movemos del marco amplio del conjunto del reino para penetrar más específicamente después en el ámbito de confrontación y colaboración entre la Corona, sus titulares, las elites aristocráticas y los actores de la esfera cortesana y por último, en los espacios concejiles. Conceptos que recorren el conjunto del monográfico, como los de bien «común»y «servicio» (o su contrario, deseruiçio, deservicio) y que se encuentran en el núcleo de la conformación política de las relaciones de poder desde la Plena Edad Media saltan a la palestra. Así, nos aparecen ya en estos trabajos dentro de una misma lógica de significación, aunque insertos en gramáticas a menudo antagónicas, proyectadas por actores en pugna por el dominio del reino, de los resortes de poder de la monarquía o de los espacios de discusión e intermediación preferentes en ella destacando en ese lugar la Corte- en sus contextos espacio-temporales específicos entre los siglos XV-XVII. Después, estamos en condiciones de ocuparnos de dinámicas discursivas de grupo más concretas, empezando por las generadas por los hidalgos norteños para luego valorar la percepción desde ambientes áulicos regios de la acción política de las comunidades urbanas y, al fin, acceder, en el plano, si se quiere, más local, a la expresión de la conciencia de los colectivos pecheros rurales frente a sus más poderosos vecinos de la caballería concejil urbana.

En este sentido, no hemos podido dejar de subrayar la relevancia del recurso a fuentes de naturaleza historiográfica -o imbuidas de una clara conciencia narrativa del tiempo y la memoria históricos- para la fijación de conceptos, procedimientos y líneas de discurso en torno a identidades sociales y concepciones del poder y su ejercicio (Sanmartín, Ortego, Pereyra, Díaz Marcilla). Tampoco puede sernos anecdótico que los diferentes textos de carácter literario abordados por los autores, ya hablemos de cronística, exégesis milenarista o tratadística de tipo político-moral, permitan acercarnos preferentemente a los posicionamientos, intervenciones y representaciones de distintos agentes pertenecientes a los sectores 
prominentes de la sociedad castellana a caballo entre el final de la Edad Media y la Temprana Modernidad: la monarquía, sus titulares y servidores cortesanos, los privados regios, la gran aristocracia, las elites hidalgas regionales e incluso grupos dominantes urbanos o colectivos eclesiásticos. El acceso a las imágenes del mundo y sus estrategias de desenvolvimiento político de los sectores populares subalternos o en posiciones intermedias entre el «común» y los colectivos dominantes, sin embargo, ha de ser desgranado preferentemente a partir de sus manifestaciones en la documentación escrita que se nos ha conservado (Mondragón).

A su vez, junto a acercamientos más atentos al análisis del texto, a su estructura o a la semántica en torno a la que se elabora el discurso -Sanmartín Barros, Ortego Rico Carzolio, Díaz Marcilla-, no faltan aquellos otros en los que el peso del bagaje teórico sociológico y antropológico adquieren un notable peso en la interpretación -Carzolio, Pereyra, Mondragón- o evidencian las tendencias de renovación, incorporación de nuevas perspectivas y diálogos entre parcelas de la ciencia histórica. Por ejemplo, Ortego Rico, por lo que toca a los nuevas aproximaciones políticas y sociales en el estudio de los orígenes de la fiscalidad «de Estado», Carzolio y Pereyra en lo referido a los últimos estudios sobre la identidad nobiliaria de las aristocracias tardomedievales y modernas y el despliegue de la «sociedad cortesana» o Mondragón a partir de un acercamiento de francos tintes microhistóricos a un caso capaz de atacar preguntas generales a partir de respuestas locales, afrontar lo global y general a partir de la observación analítica de lo individual y particular (Levi, G., 2018, pp.22-23). De un modo u otro, eso sí, los esfuerzos de renovación del acervo epistemológico, además del correspondiente a la aplicación de metodologías interdisciplinares son evidentes y, a todas luces, insoslayables, teniendo en cuenta los requisitos que la propuesta general del dossier obligada a afrontar a cada autora y autor.

Les invitamos, pues, a acompañarnos en la lectura crítica que hemos propuesto sobre discurso y política en el marco de la monarquía castellana bajomedieval y moderna. Como podrá comprobarse tras una revisión completa de estos artículos y de aquellos que les anteceden en nuestro dossier monográfico doble, los problemas en torno a la elaboración de discursos de poder difícilmente pueden disociarse de aquellos que tocan a la construcción de las identidades, sociales y políticas, desde el punto de vista del análisis histórico y, en general, de las Ciencias Sociales (Jara Fuente, J. A., 2011). Por otro lado, también podrá observarse con claridad la relevancia que adquieren, junto al conflicto, los factores de negociación y cooperación a la hora de abordar las relaciones de poder -y los procesos de comunicación y representación propagandística ligados a estas- entre esos «cuerpos complejos» de la monarquía de Castilla, en una línea similar a como se viene constatando en distintos ámbitos del Occidente entre, al menos, los siglos XIII-XVII (VV.AA., 2002; Ferrer Mallol, M. T., Moeglin, J. M., Péquignot, S., y Sánchez Martínez, M., 2005; Foronda, F. y Carrasco Manchado, A. I., 2007, 2008; Jara Fuente, J. A., 2018). En este sentido, las contribuciones aquí reunidas vienen a sumarse a una discusión ya de largo aliento que se pregunta sobre el sentido de comunidad en las sociedades medievales, las nociones y prácticas en torno a los que se conforma tal comunidad a partir de la interacción entre individuos y colectivos y las formas de la comunicación política en su seno (Dumolyn J., Haemers, J., Oliva Herrer, H. R., Challet, V., 2014; Oliva Herrer, H. R., Challet, V., Dumolyn, J., Carmona Ruiz, M. A., 2014; Carrasco Manchado, A. I., 2017a). Un debate, en fin, que conduce a cuestionar la propia noción de "política" en el horizonte del Occidente medieval y la necesidad del replanteamiento conceptual, en términos constructivos, de un proceso de "politización” que seguiría durante la Temprana Modernidad y hasta la Contemporaneidad (Bisson, T., 2010; Watts, J., 2016; Carrasco Manchado, A. I., 2017a, 2017b). Sin duda, no serán las últimas para una temática sobre la que aún queda mucho que decir.

\section{REFERENCIAS}

Bisson, T. (2010). La crisis del siglo XII. El poder, la nobleza y los origenes de la gobernación europea. Barcelona: Crítica 
Carrasco Manchado, A. I. (dir.) (2017). El historiador frente a las palabras. Lenguaje, poder y politica en la sociedad medieval: nuevas herramientas y propuestas. Lugo: Axac

Carrasco Manchado, A. I. (2017). «¿Por qué escribimos política en la Edad Media cuando queremos decir poder? Por una necesaria renovación conceptual en el estudio de la sociedad medieval», pp. 305-325. En Carrasco Manchado, A. I. (dir.), El historiador frente a las palabras. Lenguaje, poder y politica en la sociedad medieval: nuevas herramientas y propuestas. Lugo: Axac

Chartier, R. (1992). El mundo como representación. Estudios sobre historia cultural. Barcelona: Editorial Gedisa

Clavero, B. (1986). Tantas personas como estados. Por una antropología politica de la historia europea. Madrid: Tecnos

Dijk, T. A. van (2009). Discurso y poder. Contribuciones a los estudios críticos del discurso. Barcelona: Gedisa

Dumolyn, J. (2012). «Political Communication and Political Power in the Middle Ages: a Conceptual Journey», en Martín Cea, J. C. y Oliva Herrer, H. R. (coors.), La comunicación política en la Edad Media, número monográfico de Edad Media. Revista de Historia, 13, 33-55. Recuperado de: https://dialnet.unirioja.es/servlet/articulo?cod igo $=3963346$

Dumolyn, J., Haemers, J., Oliva Herrer, H. R. y Challet, V. (eds.) (2014). The Voices of the People in Late Medieval Europe. Communication and Popular Politics. Turnhout: Brepols

Fernández Albaladejo, P. (1992). Fragmentos de Monarquia. Trabajos de Historia Política. Madrid: Alianza Editorial

Ferrer Mallol, M. T., Moeglin, J. M., Péquignot, S., y Sánchez Martínez, M. (eds.) (2005). Negociar en la Edad Media. Barcelona: CSIC

Foronda, F. y Carrasco Manchado, A. I. (dirs.) (2007). Du contrat d'alliance au contrat politique: cultures et sociétés politiques dans la Péninsule Ibérique de la fin du Moyen Âge (Actes du Séminaire d'Études Médiévales de Madrid, 2005-2006). Toulouse: CNRS-Université de Toulouse-Le Mirail

Foronda, F. y Carrasco Manchado, A. I. (dirs.) (2008). El contrato político en la Corona de Castilla. Cultura y sociedad politicas entre los siglos Xy XVI. Madrid: Dykinson

Genet, J. P. (ed.) (1990). L'État moderne : genèse, bilans et perspectives. París : CNRS

Genet, J. P. (ed.) (2003). La genèse de l'État moderne. Culture et sociétépolitique en Angleterre. París: PUF

Hattori, Y. (ed.) (2014). Political Order and Forms of Communication in Medieval and Early Modern Europe. Roma: Viella

Hespanha, A. M., (1989). As vésperas do Leviathan. Instituçoes epoder politico. Portugal - Séc. XVII. Lisboa: Almedina

Howarth, D., Norval A. J. y Stavrakakis, Y. (eds.) (2000). Discourse theory and political analysis. Identities, hegemonies and social change. Manchester y New York: Manchester University Press

Jara Fuente, J. A. (2011). «Introducción. Lenguaje y discurso: percepciones identitarias y construcciones de identidad». En Jara Fuente, J. A. (coor.), La definición de la identidad urbana. Vocabulario político y grupos sociales en Castilla y Aragón en la Baja Edad Media, número monográfico de Hispania. Revista Española de Historia, 71(238), 315-324. Recuperado de: http://hispania.revistas.csic.es/index.php/hispania/article/view/344

Jara Fuente, J. A. (coord.) (2017a). Discurso politico y relaciones de poder. Ciudad, nobleza y monarquia en la Baja Edad Media. Madrid: Dykinson

Jara Fuente, J. A. (2017b). «Discurso y agencia. La reestructuración de las relaciones político-económicas entre ciudad y agentes regios: la fiscalidad regia castellana en el siglo $X V »$, pp. 305-325. En Carrasco Manchado, A. I. (dir.), El historiador frente a las palabras. Lenguaje, poder y politica en la sociedad medieval: nuevas herramientas y propuestas. Lugo: Axac

Jara Fuente, J. A. (2018). "Entre la competencia y la cooperación. Modelos de relación ciudad-nobleza a fines de la Edad Media”, Edad Media. Revista de Historia, 19, 7-15. Recuperado de: https://revistas.uva.es/index.php/ed admedia/article/view/1995/1658

Levi G. (2018). "Microhistoria e Historia Global”, Historia Crítica, 69. 21-35. Recuperado de: https://dialnet.unirio ja.es/servlet/articulo?codigo $=6483316$

Maravall, J. A. (1972). Estado moderno y mentalidad social. Siglos XV a XVII, 2 vols. Madrid: Revista de Occidente 
Martín Cea, J. C. y Oliva Herrer, H. R. (coors.) (2012). La comunicación política en la Edad Media, número monográfico de Edad Media. Revista de Historia, 13.

Menache, S. (1990). The Vox Dei. Communication in the Middle Ages. Nueva York-Oxford: Oxford University Press

Monsalvo Antón, J. M. (1986). «Poder político y aparatos de Estado en la Castilla bajomedieval. Consideraciones sobre su problemática», Studia Historica. Historia Medieval, 4, 101-167. Recuperado de: https://revistas.usal.e s/index.php/Studia_H_Historia_Medieval/article/view/4354

Monsalvo Antón, J. M. (2017). «El conflicto "nobleza frente a monarquía" en el contexto de las transformaciones del estado en la Castilla Trastámara. Reflexiones críticas», pp. 89-287. En Jara Fuente J. A. (coord.), Discurso político y relaciones de poder: ciudad, nobleza y monarquia en la Baja Edad Media. Madrid: Dykinson

Monsalvo Antón, J. M. (ed.) (2019). Élites, conflictos y discursos politicos en las ciudades bajomedievales de la Península Ibérica. Salamanca: Universidad de Salamanca

Monsalvo Antón, J. M. (2019). La construcción del poder real en la Monarquía castellana (siglos XI-XV). Madrid: Marcial Pons Historia

Nieto Soria, J. M. (dir.) (1999). Orígenes de la monarquia hispánica: propaganda y legitimación (c. 1400-1520). Madrid: Dykinson

Nieto Soria, J. M. (dir.) (2006). La monarquí como conflicto en la Corona castellano-leonesa (c. 1230-1504). Madrid: Sílex

Nieto Soria, J. M. y Villarroel González, Ó. (coors.) (2018). Comunicación y conflicto en la cultura politica peninsular siglos XIII al XV. Madrid: Sílex

Oliva Herrer, H. R., Challet, V., Dumolyn, J. y Carmona Ruiz, M. A. (coors.) (2014). La comunidad medieval como esfera pública. Sevilla: Universidad de Sevilla

Pereyra, O., y Sanmartín Barros, I. (2020). El discurso político en los cuerpos complejos de la monarquía castellana (s. XIII-XVIII). Trabajos Y Comunicaciones, 52. Recuperado de: https://www.trabajosycomunicaciones.fahce.unl p.edu.ar/article/view/TyCe120

Rucquoi, Adeline (ed.) (1987). Génesis medieval del Estado Moderno: Castilla y Navarra (1250-1370). Valladolid: Ámbito

Strayer, J. R. (2005 [1ra 1970]). On the Medieval Origins of the Modern State. Princeton: Princeton University Press

VV. AA. (2002). La propaganda politica nel Basso Medioevo(atti del XXXVIII Convegno Storico Internazionale, Todi, 14-17 octubre 2001). Spoleto: Centro italiano di studi sull'alto Medioevo

Watts, J, (2016). La formación de los sistemas politicos. Europa (1300-1500). Valencia: Publicacions Universitat de València

\section{Notas}

1 El secretario de redacción de esta publicación ha sido Sebastián Sisto (UNLP): integrante del programa PIMANT (Programa Interinstitucional del Mundo Atlántico en la Modernidad Temprana de la FaHCE-UNLP) donde se enmarca el presente proyecto editorial. El presente dossier forma igualmente parte del proyecto de investigación El ejercicio del poder: espacios, agentes y escrituras (siglos XI-XV) (Ref. HAR2017-84718-P), financiado por el Ministerio de Economía, Industria y Competitividad de España, la Agencia Estatal de Investigación y el Fondo Europeo de Desarrollo Regional de la Unión Europea.

2 Fe de errata. Primer dossier de la serie, "El discurso político en los cuerpos complejos de la monarquía castellana (s. XIII - XVIII)”. Trabajos y comunicaciones, 2020, núm. 52, Julio. En el trabajo de Elisa Caselli (Universidad Nacional de San Martín) “Juzgar a jueces. Discurso normativo regio, control judicial y poder político (Castilla, siglo XV)", tras una cita en cuerpo correspondiente a los Capítulos para corregidores y jueces de residencia de 1500 [“...Nos entendiendo que cumple a nuestro servicio y a descargo de nuestras conciencias...”] por un error involuntario en la edición, se agregó la referencia a un documento de 1492; esta referencia debía figurar más arriba, como ejemplo de instrucciones que circulaban con anterioridad a la publicación de dichos Capítulos de 1500. 